\title{
Mapping carbon sequestration potential of ultramafic rocks with remotely-sensed physical properties
}

\author{
Jamie A. CutTS ${ }^{\prime *}$, Gregory M. DiPPle', DianNe \\ MITCHINSON $^{1}$, DOMINIQUE FOURNIER ${ }^{1}$, DEJAN \\ MILIDRAGOVIC ${ }^{3}$, CRAIG J.R. HART \\ Department of Earth, Ocean and Atmospheric Sciences, \\ University of British Columbia, Canada \\ (*correspondence: jcutts@eoas.ubc.ca, \\ gdipple@eoas.ubc.ca, dmitch@eoas.ubc.ca, \\ dfournie@eoas.ubc.ca, chart@eoas.ubc.ca) \\ ¿British Columbia Geological Survey, Victoria, Canada \\ (Dejan.Milidragovic@gov.bc.ca)
}

Ultramafic rocks commonly host $\mathrm{Ni} \pm \mathrm{Cu}-\mathrm{PGE}$ mineralization and can additionally be used to sequester $\mathrm{CO}_{2}$ through mineral carbonation. In general, highly serpentinized rocks have the highest fraction of labile $\mathrm{Mg}$ for carbonation at 'ambient' earth surface conditions. Serpentinization and carbonation result in detectable changes in the physical properties of ultramafic rocksnamely magnetic susceptibility and density. Typically, serpentinization results in inceased magnetic susceptibility and decreased density and the reverse occurs during carbonation. Thus, magnetic and density properties could potentially be used to inform geophysical models to 'map' the carbon sequestration potential of ultramafic rock bodies. A major outstanding question is the degree to which these physio-chemical relationships vary among 1) rock-types in a single complex, 2) ultramafic bodies in a region, and 3) different ultramafic associations (e.g., ophiolite vs. intrusion).

This study aims to constrain the changes in physical properties associated with serpentinization and carbonation in four ophiolite complexes and one Alaskan-type intrusion in British Columbia. Preliminary data, combined with lithological observations and whole-rock major element chemistry, demonstrates that for all ophiolitic rocks there is a well-defined linear decrease in density with increased serpentinization and an inverse, albeit weaker, trend for magnetic susceptibility. For intrusive ultramafic rocks, the trends are less clear and require further investigation. Using these data, we present a deposit-scale geophysical inversion of the Decar district in central British Columbia and use this to map the most prospective rocks for carbon sequestration. This study has important implications for future mine-site infrastructure planning and may be critical for optimizing both mineral extraction and carbon sequestration. 